\title{
Role of Small Intestinal Bacterial Overgrowth in Functional Gastrointestinal Disorders
}

\author{
Chang Hwan Choi* and Sae Kyung Chang \\ Department of Internal Medicine, Chung-Ang University College of Medicine, Seoul, Korea
}

Article: Small intestinal bacterial overgrowth in patients with refractory functional gastrointestinal disorders Shimura S, Ishimura N, Mikami $\mathrm{H}$, et al

(J Neurogastroenterol Motil 2016;22:60-68)

Functional dyspepsia (FD) and irritable bowel syndrome (IBS) are the most common functional gastrointestinal disorders (FGIDs) with a significant burden on patients' quality of life. FD is defined as the presence of symptoms, including postprandial fullness, early satiation, or epigastric pain or burning, that is thought to originate in the gastroduodenal region. ${ }^{1}$ IBS is a functional bowel disorder involving abdominal pain or discomfort associated with bowel habit changes and disordered defecation. $^{2}$ An overlap between FD and IBS is commonly observed. FD and IBS are considered multifactorial disorders associated with visceral hypersensitivity, altered motility, and dysfunction of the brain-gut axis and immune system., ${ }^{2,3}$ Recently, small intestinal bacterial overgrowth (SIBO) has been suggested as a possible etiological mechanism, especially in IBS. ${ }^{45}$

$\mathrm{SIBO}$ is a condition in which there is overgrowth of bacteria in the small intestine; it is associated with symptoms such as chronic diarrhea, bloating, abdominal distention, and flatulence. ${ }^{6,7}$ These symptoms may occur due to increased gas production, toxic byproducts, de-conjugated bile salts, or increased osmotic load after bacterial metabolism in the small intestine. Bacterial overgrowth may also affect directly the sensori-motor function of the gut. ${ }^{5}$ In a recent study, mucosal interleukin (IL)- $1 \alpha$ and $\beta$ levels were higher in IBS patients with SIBO than those without SIBO, and associated with abdominal bloating, suggesting that SIBO may lead to bloating via gut inflammation. ${ }^{8}$

For the diagnosis of SIBO, small-bowel aspiration for quantitative culture has traditionally been regarded as the gold standard. Although there is no standard definition of a positive culture with studies using from more than $10^{3} \mathrm{CFU} / \mathrm{mL}$ to more than $10^{7} \mathrm{CFU} /$ $\mathrm{mL}$ to define $\mathrm{SIBO}$, a bacterial count of $10^{5} \mathrm{CFU} / \mathrm{mL}$ or more has been accepted for the diagnosis of SIBO. ${ }^{9}$ However, the limitations of this test include cost, invasiveness, potential for sample contamination, and missing bacterial overgrowth in the distal small bowel. Moreover, a large proportion of luminal bacteria goes uncultured. ${ }^{9}$ Thus, breath testing has been used as an alternative approach to diagnose SIBO.

Breath testing is more readily available, safe, inexpensive, and noninvasive than jejunal aspiration culture for the diagnosis of SIBO. Furthermore, it may represent both proximal and distal small bowel bacterial overgrowth when lactulose is used as a substrate, and thus includes cases of pathologic bacterial strains not cultured. ${ }^{5,9}$ Breath testing involves administering a load of carbohydrate, such as ${ }^{14} \mathrm{C}$-xylose, lactulose, or glucose to patients, and mea-

Received: December 12, 2015 Revised: None Accepted: December 14, 2015

(c) This is an Open Access article distributed under the terms of the Creative Commons Attribution Non-Commercial License (http://creativecommons. org/licenses/by-nc/4.0) which permits unrestricted non-commercial use, distribution, and reproduction in any medium, provided the original work is properly cited.

*Correspondence: Chang Hwan Choi, MD, PhD Department of Internal Medicine, Chung-Ang University College of Medicine, 102 Heukseok-ro, Dongjak-gu, Seoul 06973, Korea Tel: +82-2-6299-1418, Fax: +82-2-6299-2017, E-mail: gicch@cau.ac.kr 
suring exhaled gas concentrations produced by bacterial fermentation over a period of time. Thus, the luminal bacterial load can be assessed indirectly. The measured gases include labeled carbon dioxide $\left(\mathrm{CO}_{2}\right)$, hydrogen, and methane. Hydrogen breath testing (HBT) after ingestion of lactulose or glucose is the most commonly used method, based on the principle that exhaled hydrogen and methane are solely produced by bacterial fermentation of carbohydrates. The measurement of methane in addition to hydrogen may improve the diagnostic yield of breath testing, because $20 \%$ to $30 \%$ of the general population produces methane as the main by-product of carbohydrate fermentation.,

Although there are many advantages of breath testing, this testing modality also has several limitations in the diagnosis of SIBO, which include heterogeneous testing methods and interpretation. The typical protocol of the lactulose hydrogen breath test (LHBT) includes oral ingestion of $10 \mathrm{~g}$ lactulose in $200 \mathrm{~mL}$ water; next, breath samples are collected at 15-minute intervals for 120-240 minutes. Positive tests include a fasting hydrogen level of $\geq 20$ parts per million (ppm), a double peak with hydrogen levels, an early increase of $\geq 20 \mathrm{ppm}$ (within 90 minutes), or a sustained increase of $\geq 10 \mathrm{ppm}$ over baseline hydrogen levels. ${ }^{5,9}$ However, a variety of test methods and diagnostic criteria are used in studies, and they are not standardized to define a positive test for SIBO. Among the various diagnostic LHBT criteria for SIBO, the earlypeak criterion, which has been most commonly used, can overdiagnose SIBO, because the pattern of gas production in subjects with rapid small bowel transit is similar to that in patients with SIBO. In contrast, glucose hydrogen breath test (GHBT) may underestimate the frequency of SIBO by missing bacterial overgrowth in the distal small bowel, because glucose is completely absorbed in the proximal small bowel. In most studies, a glucose dose ranging from 50 to 100 $\mathrm{g}$ was used, and breath samples were collected for 120-240 minutes. The definition of a positive result ranges from an increase in exhaled hydrogen from 10 to $12 \mathrm{ppm}$ compared to the baseline, but the GHBT also does not have a standard for the performance or interpretation. ${ }^{5,9}$ An additional problem of breast testing is that there is no reliable or reproducible gold standard for diagnosis of SIBO. So, breath test results are difficult to interpret properly. Thus, the sensitivity and specificity of breast testing for the diagnosis of SIBO are quite variable, ranging $17 \%$ to $68 \%$, and $44 \%$ to $86 \%$ for LHBT, respectively. The accuracy of GBT also varies, with sensitivity ranging from $20 \%$ to $93 \%$, and specificity ranging from $30 \%$ to $86 \%$. Based on the results of 11 cross-validation clinical trials that compared HBTs and jejunal aspirate culture, the expert working group suggested that the GHBT is a more accurate testing modality than
LHBT for the diagnosis of suspected SIBO in their consensus document. ${ }^{10}$

In the current issue of the Journal of Neurogastroenterology and Motility, Shimura et $\mathrm{al}^{11}$ have published a prospective study in which they investigated the frequency of SIBO in patients with refractory FGID, and assessed the efficacy of antibiotics in patients with SIBO. The frequency of SIBO assessed by GBT was only 2 (5.3\%) out of 38 patients with refractory FGID (1 with FD and 1 with overlapping FD and IBS). This low prevalence of SIBO may be due at least in part to the low sensitivity of GBT for the diagnosis of SIBO. Although the prevalence of SIBO was very low, patients' symptoms clearly improved and breath hydrogen levels normalized following levofloxacin administration.

The symptoms of SIBO and IBS overlap, since SIBO can lead to similar physiologic changes as those observed in patients with IBS. ${ }^{5,7}$ Some research data indicated an increased prevalence of SIBO in IBS, and an improvement in IBS symptoms with antibiotic treatment, ${ }^{42-14}$ However, the link between SIBO and IBS is not definitive. First, the relationship between these 2 conditions is largely based on HBT, and the frequency of SIBO varies considerably from $4 \%$ to $78 \%$ in patients with IBS, and from $1 \%$ to $40 \%$ among healthy controls due to the lack of standardization of $\mathrm{HBT}^{4,5}$ Secondly, it remains unclear whether SIBO is a cause of IBS, or instead a bystander associated with other abnormalities underlying IBS. For example, abnormal LHBT results may reflect underlying dysmotility in IBS, because dysmotility (eg, scleroderma) can likely cause SIBO ${ }^{6,15}$ The improvement of IBS symptoms with antibiotics does not necessarily indicate that SIBO causes IBS, but instead may be a beneficial effect on a troublesome epiphenomenon, such as bloating caused by SIBO. Finally, antibiotics may reduce IBS symptoms by affecting colonic bacteria rather than, altering small intestinal bacteria. The colonic microbial dysbiosis found in IBS patients may support this hypothesis. ${ }^{15}$ Thus, controversy remains regarding the relationship between SIBO and IBS.

Currently, treatments for patients with IBS or FD are still limited to symptomatic therapy. Patients with FGIDs who do not respond to initial gut-acting pharmacologic agents can be managed with antidepressants and other psychosocial therapies. ${ }^{3}$ However, those treatments may also not be satisfactory for some patients with refractory symptoms. Thus, performing tests and treatments for SIBO may be a useful option for patients with refractory FGID, regardless of whether SIBO is the cause of refractory FGID or just an epiphenomenon, even if the prevalence of SIBO is low among them. In the future, the application of molecular techniques to the characterization of the small intestinal microbiome will help us de- 
fine what is normal, and identify alterations in the flora responsible for symptoms and disease.

\section{Financial support: None.}

\section{Conflicts of interest: None.}

Author contributions: Chang Hwan Choi drafted and edited the manuscript; and Sae Kyung Chang reviewed and advised on editing the manuscript.

\section{References}

1. Tack J, Talley NJ, Camilleri M, et al. Functional gastroduodenal disorders. Gastroenterology 2006;130:1466-1479.

2. Longstreth GF, Thompson WG, Chey WD, Houghton LA, Mearin F, Spiller RC. Functional bowel disorders. Gastroenterology 2006;130: 1480-1491.

3. Spiller R, Aziz Q, Creed F, et al. Guidelines on the irritable bowel syndrome: mechanisms and practical management. Gut 2007;56:1770-1798.

4. Ford AC, Spiegel BM, Talley NJ, Moayyedi P. Small intestinal bacterial overgrowth in irritable bowel syndrome: systematic review and metaanalysis. Clin Gastroenterol Hepatol 2009;7:1279-1286.

5. Ghoshal UC, Srivastava D. Irritable bowel syndrome and small intestinal bacterial overgrowth: meaningful association or unnecessary hype. World J Gastroenterol 2014;20:2482-2491.

6. Quigley EM. Small intestinal bacterial overgrowth: what it is and what it is not. Curr Opin Gastroenterol 2014;30:141-146.

7. Lin HC. Small intestinal bacterial overgrowth: a framework for understanding irritable bowel syndrome. JAMA 2004;292:852-858.

8. Srivastava D, Ghoshal U, Mittal RD, Ghoshal UC. Associations between IL-1RA polymorphisms and small intestinal bacterial overgrowth among patients with irritable bowel syndrome from India. Neurogastroenterol Motil 2014;26:1408-1416.

9. Saad RJ, Chey WD. Breath testing for small intestinal bacterial overgrowth: maximizing test accuracy. Clin Gastroenterol Hepatol 2014;12: 1964-1972.

10. Gasbarrini A, Corazza GR, Gasbarrini G, et al. Methodology and indications of H2-breath testing in gastrointestinal diseases: the Rome Consensus Conference. Aliment Pharmacol Ther 2009;29(suppl 1):1-49.

11. Shimura S, Ishimura N, Mikami H, et al. Small intestinal bacterial overgrowth in patients with refractory functional gastrointestinal disorders. J Neurogastroenterol Motil 2016;22:60-68.

12. Menees SB, Maneerattannaporn M, Kim HM, Chey WD. The efficacy and safety of rifaximin for the irritable bowel syndrome: a systematic review and meta-analysis. Am J Gastroenterol 2012;107:28-35.

13. Ghoshal UC, Kumar S, Mehrotra M, Lakshmi C, Misra A. Frequency of small intestinal bacterial overgrowth in patients with irritable bowel syndrome and chronic non-specific diarrhea. J Neurogastroenterol Motil 2010;16:40-46.

14. Goebel-Stengel M, Stengel A, Schmidtmann M, Voort I, Kobelt P, Mönnikes H. Unclear abdominal discomfort: pivotal role of carbohydrate malabsorption. J Neurogastroenterol Motil 2014;20:228-235.

15. Spiegel BM. Questioning the bacterial overgrowth hypothesis of irritable bowel syndrome: an epidemiologic and evolutionary perspective. Clin Gastroenterol Hepatol 2011;9:461-469. 